\title{
A Brief Analysis on the Teaching Method of Police's Pistol Shooting Class
}

\author{
Dongbai Guo
}

\author{
Department of Police tactical training,Criminal Investigation Police University of China, Shenyang, \\ Liaoning, 110035 \\ guodongbai@cipuc.edu.cn
}

\section{Keywords: Police; Pistol; Shooting; Teaching method}

\begin{abstract}
Tshooting teaching is the teaching subject with the most distinctive police industry features and the required course to the students at police training school. With the teaching practice and exploration over years, the author has acquired unique understanding and mastery for the teaching laws of the course. The pistol shooting teaching at the police training school is to not only enable the students to master the shooting theories but also take the good teaching opportunity to cultivate their operating skills, foster their strong wills, good psychological qualities and staunch styles by mastering the related technical knowledge and making actual practice to meet the demands of actual combat and improve the teaching quality of the shooting class. Due to its small size, light weight and convenience to carry and use, pistol is the weapon used by police at point-blank range to fight criminals and defend themselves. It's one of the basic skills that the police must master to shoot with pistol. Shooting teaching method is an important content in the shooting training. It focuses on the basic principle of shooting training and method for type of organization to serve the ultimate goal of shooting training - to shoot accurately. Therefore, during learning and applying the teaching method, we shall be practical, make continuous conclusion, are to explore to make it more in line with the requirements of the modern teaching. Flexible and diverse teaching and training methods are adopted as the basic means to guide training as well as the fundamental way and belt to improve skills.
\end{abstract}

\section{Current Status of Shooting Teaching}

Teaching content. Basic shooting is essential to shooting training that requires the students to master the basic theories of firearms. Many public security schools emphasize foundation and adopt the single shooting action without the shooting training in various posture and position changes. They stress action details and require precision and number of ring during shooting while ignoring the requirements of taking the pistol out and shooting rapidly, hence less cultivation and training of tactical consciousness. Although the basic shooting is an insurmountable basic stage in the entire teaching process, many teachers at the police training schools have paid too much attention to the basic shooting actions instead of further teaching the practical and tactical shooting methods. Such teaching and training will undoubtedly cause endless troubles. When they are performing the combat mission, the police will always act in line with the habit developed on the shooting range, which means instead of shooting rapidly at the armed criminals, they rise the pistol, aim at the goal and shoot as they are trained daily. There will be loss easily for they have lost the opportunities. According to the survey made by the Americans, a considerable number of the police shot in gunfight are excellent shooters on the shooting range. The requirements will be even lower when we are training the in-service policemen, they are only required to be capable of loading bullets and shooting accurately; even worse, the basic common sense of safety operation has been ignored.

Teaching effect. After the trainees have finished the shooting class, their hooting levels will differ greatly. Some of them will be excellent, some will be barely qualified and a small part will be unqualified. It is closely related to the training consciousness and initiative of the trainees. Those who have trained seriously and consciously with better comprehension will master the essential of actions well; those who have poor comprehension can only reach the lowest requirements. 
Therefore, it is very important to fully arouse the enthusiasm of the trainees during the daily training while the teacher shall play the due role in supervision and encouragement, so that each trainee can better master the essentials of shooting and achieve the best teaching effect of shooting. There are two extremes in training the in-service policemen. One, as they have very few opportunities to contact with guns, although being trained, they will be overstrung, so that the actions are deformed and the training effect will be influenced. Two, they will be overconfident that believe they have comprehensively mastered the essentials and regulations of shooting, so that they will be too careless and unconcerned to ignore the importance of the safety operation standards on the shooting range; there will be problems such as toying with guns and disobeying the orders to influence the normal training.

The input resources. Due to the insufficient cost, many schools have no hardware facilities necessary in shooting teaching. Also, the number of bullets used for teaching is seriously insufficient, so that the trainees have extremely limited opportunities to train with live ammunition. Pistols for teaching and training are also seriously damaged, police firearms used for teaching are of few varieties, the trainees are incapable of using the front-line equipment and other machine pistols, baton guns and special firearms. According to data, the American police have to finish the shooting training of 30 hours with 6000 bullets before they get the job. The Hong Kong police will be equipped only after they have finished the valid shooting training with the 300 live ammunitions. On the other hand, very few trainees at the public security schools training the probationary police can finish the firing practice with more than 120 bullets during the school days.

\section{Objectives of Pistol Shooting Teaching and Training}

To establish and strengthen the trainees' legal consciousness of using weapons legally and effectively. There are specific regulations on how the police shall use weapons legally in the laws and regulations such as Law of People's Police, Firearms Control Act and Regulations on People's Police Using Police Equipment and Weapons. It's a major and even embarrassed situation that many police dare not to use weapons legally during performing the official business. They shall completely understand by learning the related laws and regulations that they can shoot decidedly when the situation is totally in conformity with the conditions for the police to use weapons.

To improve the trainees' safety consciousness physical psychological qualities of using firearms. After the learning and training, the trainees' consciousness of keeping, using the firearms safely as well as the safety consciousness during the training can be improved to make sure they can be safe in the training as well as being equipped and using firearms to perform official business in the future. Police is one of the most stressful occupations in society. The metal pressure index borne by police during work is in the forefront beyond controversy. Especially when they are facing with the criminal suspects and the extremely vicious criminals, need to enforce the law with their weapons, the mental pressure will reach the peak. Therefore, during the training, we shall try the best to enhance their psychological endurance and spirit of decisiveness and fearlessness.

To make the trainees master the excellent skills. After the learning and training, the trainees shall be capable of comprehensively mastering the specification requirements of shooting actions and shooting skills, so that they can be brave in dangerous situations and bring the criminals under control tactfully and effectively when they are handling the violent and terrorist crimes. It is in this method can they achieve their goal of protecting the people's life and property safety and becoming an defender of our country that demanded at the grass-roots unit and trusted by our people.

\section{Exploration on the Shooting Teaching Method}

Modes in the shooting teaching. Training on the continuous shooting shall be strengthened at the same time of shooting the same target $t$ short range. It means that there shall be two continuous shootings at each shot. From the combat perspective of combat, it is to suppress the firepower of each other, enhance the shooting effect and ensure the personal safety; from the medical perspective, nearly $20 \%$ of those who are shot in shooting accident won't be bowled out; even with 
fatal wound, some of them can act for more than five minutes with considerable destructive power and danger level. It is of combat significance to strengthen the continuous shooting training.

Psychology in shooting teaching. In the actual combat, under pressures such as rapidly changing and transient situations, complicated surrounding environment in addition to the cunning and murderous criminal suspects, it is extremely important for the shooters to keep clam. Facing the suspects of violent crimes, the shooter might shoot earlier and hinder military operations for he will be excited and overstrung as a result of various external simulations. During the shooting teaching, it is common that the first and last examination results of the live ammunition shootings are undesirable out of extreme nervousness; therefore, psychological training is indispensable. Through the training, the trainees can carry out shooting training under pressure to improve their capacities of controlling their conceptual work effectively and adjusting their mental state consciously.

White target practice method. The objective of this practice is white target paper, open space; without specific aiming point, it's easy to focus attention, correct the defect of forward moving vision with rigorous demand for aiming; it also can correct the problems in pulling the trigger, i.e. daring not to pre-press the trigger or rushing to pull the trigger. It is the most beneficial to establish the correct action concept by carrying out empty-gun aiming practice and live ammunition shooting practice at the white targets with different distances. It can improve the trainees' consciousness of pulling the trigger, mastering the correct method of pulling the trigger and coordinating the pulling and aiming actions to greatly enhance the trainees' scores in the pistol shooting consistency and precision of hitting the target.

Density practice method. The density shooting training is to shoot the certain number of bullets at the target (i.e. the chest ring target). Instead of focusing on the point of bullet contact (not focusing on the result) during the shooting process, we shall pay attention to making the action of each bullet and try the best to reconcile the actions of each time. The density shooting training can enhance and solidify the correct big action concept, improve the action consistency. By the density shooting training, we can check the action quality and enhance the confidence of the action. The density shooting training can also calculate the mean point of bullet contact of the shot bullets according to the distribution of the points of bullet contact, so as to determine the deviation of firearms and provide basis to correct the sighting device or aiming area in the precision shooting.

The police pistol shooting teaching is concerned increasingly and greatly by the leaders of all levels. It becomes more and more important to strengthen the exploration and analysis on the police pistol shooting training. As there are various methods for the police pistol shooting teaching and training, we shall make continuous effort in enhancing and improving the methods for police pistol shooting teaching and training, try the best to improve the training effect, strengthen the police capacity of mastering and using weapons. To fight crimes, maintain social security and stability and protect people's life and property safety, the training effect shall be turned into the powerful police strength as soon as possible

\section{References}

[1] Zaho Lingyun. Shooting Teaching Reform under the Background of Changed Concept of Police using Guns [J]. Journal of Hubei University of Police, 2015 (7).

[2] Lin Xiangfei, Wang Lei. In-depth Exploration on Shooting Teaching Reform-from the perspective of relocating the teaching objectives [J]. Sports World Scholarly 2017 (4).

[3] Wu Ying. A Brief Analysis on Teaching Method of Police Sports Shooting [J]. Science \& Technology Vision, 2016(6).

[4] Jun, Some Thoughts on Strengthening Police Shooting Training in China at the New Period [J]. Journal of Chinese People's Armed Police Force Academy, 2014 (1).

[5] Liu Long. Influences of Mental Workload on the Police Shooting Precision [J]. Contemporary Sports Technology, 2015 (10).

[6] Hu Kongfa. Database Principle and Application [M]. Beijing: China Machine Press, 2015:127.

[7] Deng Yanting. Rapid Analysis and Design of Database Based on Normal Form [D]. Anhui University of Science and Technology, 2014. 
[8] Wei Honglei. Discussion on the Police's Psychological Training of Shooting [J]. Journal of Guangxi Police College, 2015 (9)

[9] Wang Min. Inspiration of Legal System on Extraterritorial Police Using Guns [J]Journal of Chinese People's Public Security University (social science edition), 2015 (3).

[10] Zhang Jun. A Research on the Construction of Pistol Tactical Shooting System [J]. Journal of The Armed Police Academy, 2015 (9). 